\title{
Hablamos juntos (together we speak): a brief patient-reported measure of the quality of interpretation
}

This article was published in the following Dove Press journal:

Patient Related Outcome Measures

9 September 2014

Number of times this article has been viewed

Efrain Talamantes'

Gerardo Moreno²

Lourdes R Guerrero ${ }^{3}$

Carol M Mangione $\mathrm{e}^{3,4}$

Leo S Morales ${ }^{5,6}$

'US Department of Veterans Affairs and Division of General Internal Medicine, Division of General Internal Medicine and Health Services Research, University of California Los Angeles, CA, ${ }^{2}$ Department of Family Medicine, University of California Los Angeles, Los Angeles, CA, ${ }^{3}$ Department of Medicine, Division of General Internal Medicine and Health Services, University of California Los Angeles, Los Angeles, CA, ${ }^{4}$ School of Public Health, University of California Los Angeles, Los Angeles, CA, ${ }^{5} \mathrm{Group}$ Health Research Institute, Seattle, WA, ${ }^{6}$ Center for Health Equity, Diversity and Inclusion, School of Medicine, University of Washington, Seattle, WA, USA
Correspondence: Efrain Talamantes Division of General Internal Medicine and Health Services Research, University of California Los Angeles, 10940 Wilshire Blvd, Suite 7I0, Los Angeles, CA 90024, USA

$\mathrm{Tel}+\mathrm{I} 3107942257$

Fax + I 3107943288

Email etalamantes@mednet.ucla.edu
Purpose: This study evaluates the psychometric properties of three newly developed items assessing the quality of interpretation from the patient's perspective among Spanish-speaking limited English proficient Latino patients.

Patients and methods: The authors examined the psychometric properties of a patientreported measure of quality of interpretation using a cross-sectional survey study of 1,590 adult Spanish-speaking limited English proficient Latinos in the United States. Quality of interpretation, doctor communication, and satisfaction with care were assessed using a three survey-item, an independent multiple-item measure, and a single-item measure, respectively.

Results: Sixty-nine percent $(1,104)$ of patients surveyed used interpreters. Cronbach's alpha for the three items assessing interpreter quality was 0.31 , while dropping item three resulted in an alpha of 0.56 . Items one and two were moderately correlated with doctor communication $(r=0.39)$ and satisfaction with care scores $(r=0.21)$ supporting construct validity.

Conclusion: Two out of three survey items can be scaled to measure quality of interpretation from the patient's perspective. Quality of interpretation reported by patients is moderately associated with doctor communication and satisfaction with care.

Keywords: interpreters, Latinos, doctor-patient communication, satisfaction with care

\section{Introduction}

Health care professionals and organizations in the US are caring for an increasing number of Latino patients. Latinos are a diverse ethnic group that includes many different cultures, races, nationalities, and share a common language. Over 35 million people speak Spanish at home and 50\% are limited English proficient (LEP). ${ }^{1,2}$ LEP individuals are not able to speak, read, write, or understand the English language at a level that permits them to communicate effectively with health care providers. ${ }^{3}$ Language barriers between health care providers and patients have been documented as a primary cause of health disparities in Latinos..$^{4-8}$ The National Standards on Culturally and Linguistically Appropriate Services (CLAS) developed by the Office of Minority Health, and the Joint Commission on Accreditation of Healthcare Organizations (JCAHO) require health care professionals to determine the communication and language assistance needed for individuals with LEP. ${ }^{9}$ However, hospitals are not providing language services in a manner consistent with the federal law and it is unclear how interpreter services are developed, implemented, or evaluated. ${ }^{10}$

The use of professional interpreters is a financially viable method for enhancing delivery of health care to patients, ${ }^{11}$ decreasing communication errors, increasing 
patient comprehension, equalizing health care utilization, improving clinical outcomes, and increasing satisfaction with communication and clinical services for LEP patients. ${ }^{12}$ Among Spanish-speaking LEP Latino patients, interpreter use was associated with higher satisfaction with doctor communication, office staff helpfulness, and ambulatory care. ${ }^{13}$ The use of an interpreter was also independently associated with receiving explanations about possible medication side effects, directions, and purpose. ${ }^{14}$ Whereas these studies support the use of interpreters, none examine the specific attributes of high quality interpretation from the patient's perspective.

The purpose of this study is to evaluate the psychometric properties of the three newly developed items assessing the quality of interpretation from the patient's perspective among Spanish-speaking LEP Latino patients. The association between the patient-reported interpreter quality and communication with providers and satisfaction with care was also examined.

\section{Methods \\ Data Source}

We analyzed pooled cross-sectional survey data collected in two waves between 2003 and 2006 from 1,590 Latino adult LEP women and men who participated in the Hablamos Juntos (HJ) national demonstration project. HJ was funded by the Robert Wood Johnson Foundation to improve doctor-patient communication by increasing access to and improving the quality of interpreter services for Spanishspeaking patients.

In the HJ survey, patients chose to complete the interview in Spanish or English using computer-assisted telephone interviews. Survey response rates ranged from $45 \%$ to $85 \%$ across sites. The survey did not collect objective or detailed information on the type of interpreter used (ad-hoc versus professional). However, sites were included into this study in part for their need of interpreter services. When bilingual providers provided patient care, no interpreter was needed. A general evaluation of the HJ national demonstration project including a description of the study sites has been published elsewhere. ${ }^{13}$

\section{Measures}

Patients were classified into three groups based on their need for and use of interpreters in the last 6 months. These categories were: 1) interpreter not needed; 2) interpreter needed and used always, usually, or sometimes; and 3) interpreter needed but not used. Patients who used interpreters always, usually, or sometimes were asked three questions about the quality of interpreters they used in the past 6 months: 1) how often did the interpreters listen carefully; 2) how often did the interpreters repeat all of their questions to the provider; and 3) how often did the interpreters use words that were hard to understand? Prior literature identified these survey items as major challenges patients identify when using an interpreter to communicate with their medical providers. ${ }^{15}$

The psychometric property of content validity for questions about the quality of interpretation was then assessed with a separate four-item measure asking questions about doctor communication in the last 6 months (item 1, listening carefully; item 2, repeating questions; item 3, using words that are hard to understand; and item 4, spending enough time with patients) and a single global item measure of satisfaction with ambulatory health care during the last 6 months (score range of 0-10). A composite score of provider communication was computed by linearly transforming each item score to a 0-100 metric, then computing the average score among the four items. Other covariates included in the analysis were age (18-29, 30-44, or $\geq 45$ years), education (0-6, 7-11, or $\geq 12$ years), sex (male, female), marital status (married, separated/divorced/widowed, or single/never married), income (less than half of the poverty level, half at the poverty level, or above the poverty level), birthplace (United States, Mexico, Central America, or Caribbean), and self-reported health status (excellent, very good, good, fair, or poor).

\section{Statistical analyses}

Stata version 11.1 (StataCorp LP, Texas, USA) was used to conduct all analyses. First, item means, standard deviations, non-response rates, and item response frequencies, including ceiling and floor category endorsement rates, were determined. Inter-item correlation coefficients, itemscale correlation coefficients, and Cronbach's alpha for the three-item scale were also calculated. To assess the construct validity, correlations between each item, the scale score, and the measures of doctor communication and satisfaction with health care were computed. Linear regression analyses were then used to assess the association between the patientreported interpretation quality, and doctor communication and satisfaction with care.

\section{Results}

Table 1 is a summary of the sociodemographic, insurance coverage and health status characteristics of the $69 \%$ $(n=1,104)$ study participants, who were eligible for this study because they used an interpreter in the past 6 months. The majority of the study participants were older (73\%), insured (66\%), Latina women (82\%), with less than a high school 
Table I Sociodemographic characteristics, insurance coverage, and health status among Hablamos Juntos survey participants $(\mathrm{N}=\mathrm{I}, \mathrm{I04})$

\begin{tabular}{|c|c|c|}
\hline Participant characteristics & $\mathbf{n}$ & $\%$ \\
\hline \multicolumn{3}{|l|}{ Age (years) } \\
\hline $18-29$ & 292 & 27 \\
\hline $30-44$ & 466 & 42 \\
\hline$>45$ & 346 & 31 \\
\hline Female & 909 & 82 \\
\hline \multicolumn{3}{|l|}{ Education (years) } \\
\hline $0-6$ & 475 & 43 \\
\hline $7-11$ & 324 & 29 \\
\hline$>12$ & 305 & 28 \\
\hline \multicolumn{3}{|l|}{ Marital status } \\
\hline Married & 615 & 56 \\
\hline Separated, divorced, widowed & 244 & 22 \\
\hline Never married, single & 237 & 22 \\
\hline Insured & 728 & 66 \\
\hline \multicolumn{3}{|l|}{ Family income* } \\
\hline Less than half the poverty level & 240 & 27 \\
\hline Half to at the poverty level & 338 & 39 \\
\hline Above the poverty level & 297 & 34 \\
\hline \multicolumn{3}{|l|}{ Birthplace } \\
\hline United States & 24 & 2 \\
\hline Mexico & 634 & 58 \\
\hline Central America & 66 & 6 \\
\hline Caribbean & 156 & 14 \\
\hline South America/other & 220 & 20 \\
\hline \multicolumn{3}{|l|}{ Self-reported health status } \\
\hline Excellent & 73 & 7 \\
\hline Very good & 95 & 8 \\
\hline Good & 338 & 31 \\
\hline Fair & 496 & 45 \\
\hline Poor & 96 & 9 \\
\hline
\end{tabular}

Notes: *Poverty level was calculated using the US federal poverty guidelines. Two items were used to determine poverty level including: I) the number of people supported by income that respondent and/or their spouse or partner earn; and 2) total household income amount. The English translation for Hablamos Juntos is "Together we speak".

Abbreviations: $\mathrm{N}$, total number of subjects; $\mathrm{n}$, portion of subjects.

education (74\%), from Mexico (58\%), and reported fair to good health status $(76 \%)$.

Table 2 shows the three survey items used to measure quality of interpretation from the patient's perspective. Interpreters always listened carefully (65\%), always repeated questions $(59.2 \%)$, and never used words that were hard to understand (45.2\%). Item (1), "listen carefully", had a mean score of 3.66 (standard deviation [SD] $=0.70), 1.5 \%$ at the floor, and $65 \%$ at the ceiling. Item (2), "repeat all patients questions", had a mean score of 3.49 ( $\mathrm{SD}=0.88$ ), 3.4\% at the floor, and $59.2 \%$ at the ceiling. Item (3), "interpreters use words that are hard to understand", had mean score of 3.17 ( $\mathrm{SD}=1.09$ ), $45.2 \%$ at the floor, and $12.8 \%$ at the ceiling.

Item (1) "listen carefully", and item (2) "repeat all patients questions" were positively correlated $(r=0.40, P<0.001)$. Item (3) "interpreters use words that are hard to understand" was not correlated with items (1), and (2). Cronbach's alpha for all three items measuring interpretation quality was 0.31 and increased to 0.56 when the last item ("interpreters use words that were hard to understand") was dropped. The composite for items (1) and (2) had a correlation of 0.40 $(P<0.001)$ with doctor communication, and $0.28(P<0.001)$ with satisfaction with care. Item (3) was not correlated with doctor communication or satisfaction with care.

Patients who reported that their interpreters always listened carefully and repeated questions also rated their doctor communication and overall satisfaction with care higher than those that usually or never/sometimes listened carefully or repeated questions $(P<0.001)$. Satisfaction with overall care mean scores $(0-100)$ when interpreters listened carefully were as follows: never/sometimes (mean 78.4, SD 20.1); usually (mean 83.1, SD 17.8); always (mean 91.9, SD 13.9). Satisfaction with overall care scores (0-100) when interpreters repeated questions were as follows: never/sometimes (mean 82.7, SD 22.1); usually (mean 84.7, SD 15.2); always (mean 91.9, SD 13.2). Satisfaction with overall care scores $(0-100)$ when interpreters used words that were hard to understand were as follows: never/sometimes (mean 92.1, SD 13.1); usually (mean 83.6, SD 18.3); always (mean 91.9, SD 16.7). Using words that were hard to understand had a low correlation with the doctor communication composite score and satisfaction with overall care.

Table 2 Survey items to measure patient experiences with the quality of interpretation among Hablamos Juntos participants who used interpreters $(\mathrm{N}=\mathrm{I}, 104)$

\begin{tabular}{|c|c|c|c|c|c|c|c|c|}
\hline Survey item & $\mathbf{N}$ & Mean & SD & Never & Sometimes & Usually & Always & No response \\
\hline & & & & n (\%) & n (\%) & n (\%) & n (\%) & n (\%) \\
\hline $\begin{array}{l}\text { How often did these interpreters listen } \\
\text { carefully? }\end{array}$ & $\mathrm{I}, 104$ & 3.66 & 0.70 & $15(1.5)$ & I0I (7.7) & I 28 (9.8) & $850(65.0)$ & $10(0.01)$ \\
\hline $\begin{array}{l}\text { How often did these interpreters repeat } \\
\text { all of your questions to your doctor? }\end{array}$ & $\mathrm{I}, 104$ & 3.49 & 0.88 & $45(3.4)$ & I5I (II.6) & II 5 (8.8) & $774(59.2)$ & I5 (0.0I) \\
\hline $\begin{array}{l}\text { How often did these interpreters use } \\
\text { words that were hard to understand? }\end{array}$ & 1,104 & 3.17 & 1.09 & 591 (45.2) & $260(19.9)$ & 7I (5.4) & $167(12.8)$ & $19(0.02)$ \\
\hline
\end{tabular}

Note: The English translation for Hablamos Juntos is "Together we speak".

Abbreviations: SD, standard deviation; $\mathrm{N}$, total number of subjects; $\mathrm{n}$, portion of subjects. 
Figure 1 shows doctor communication adjusted composite scores as they relate to each patient's reported measure of the quality of interpreters. Doctor communication composite score is statistically significantly better when interpreters always listen carefully and repeat questions compared to when they only do this usually, or never/sometimes. Interpreter's use of words that are hard to understand did not show a graded or significant pattern of association with doctor communication.

\section{Discussion}

This study found that two of the three items evaluated are scalable and could be used to measure the quality of interpretation from the patient's perspective. The two items ask about whether the interpreter listened carefully and whether the interpreter repeated all of the patient's questions to the doctor. Each of these items asks about an important aspect of medical interpretation and addresses actionable content usable for quality improvement purposes. Alternatively, these two items can be scaled to produce a single score assessing the quality of interpretation.

Patients reported better communication with providers and higher satisfaction with care when interpreters "listen carefully" (item 1) and "repeat all patient questions" (item 2) to doctor with a greater frequency in this study. Item (3), "interpreters use words that are hard to understand", was likely not scalable due to the impact of using a negatively phrased item in the survey where the other items were positively phrased, or possibly because the commonly used medical jargons and technical terms are difficult to understand regardless of who uses them. Interpreters overcome the overwhelming task of translating words that are hard to understand and simplifying terms and concepts in a culturally congruent manner. Despite these challenges, communication between doctors and LEP patients through professional interpreters is associated with fewer communication errors, better patient comprehension, improved clinical outcomes, and higher satisfaction with communication. ${ }^{12}$ Therefore, monitoring and improving the quality of medical interpretation based on patient reports may lead to improved patient outcomes on multiple dimensions.

This is one of the first studies to report a measure of quality of interpretation by medical interpreters from the patient's perspective. Previous studies have examined global satisfaction with interpreters and patient satisfaction with different interpretation modalities and our results expand the literature by focusing on unique aspects of the quality of interpretation from the patient's perspective. ${ }^{16-19}$ Traditional assessment of the quality of interpreters has focused on the interpreter qualifications and training without incorporating the patient experience. ${ }^{20}$ Prior efforts attempt to capture the quality of interpreters by measuring the interpreters' ability (eg, certifications) and other technical aspects of language interpretation. This study shows that incorporating patientcentered measures of quality may help discriminate the interpreter effectiveness during the delivery of care to LEP patients.

The results indicate that all three items on perceptions of interpreter quality are not scalable. Cronbach's alpha for all three items was low at 0.31 . The item that asked patients about

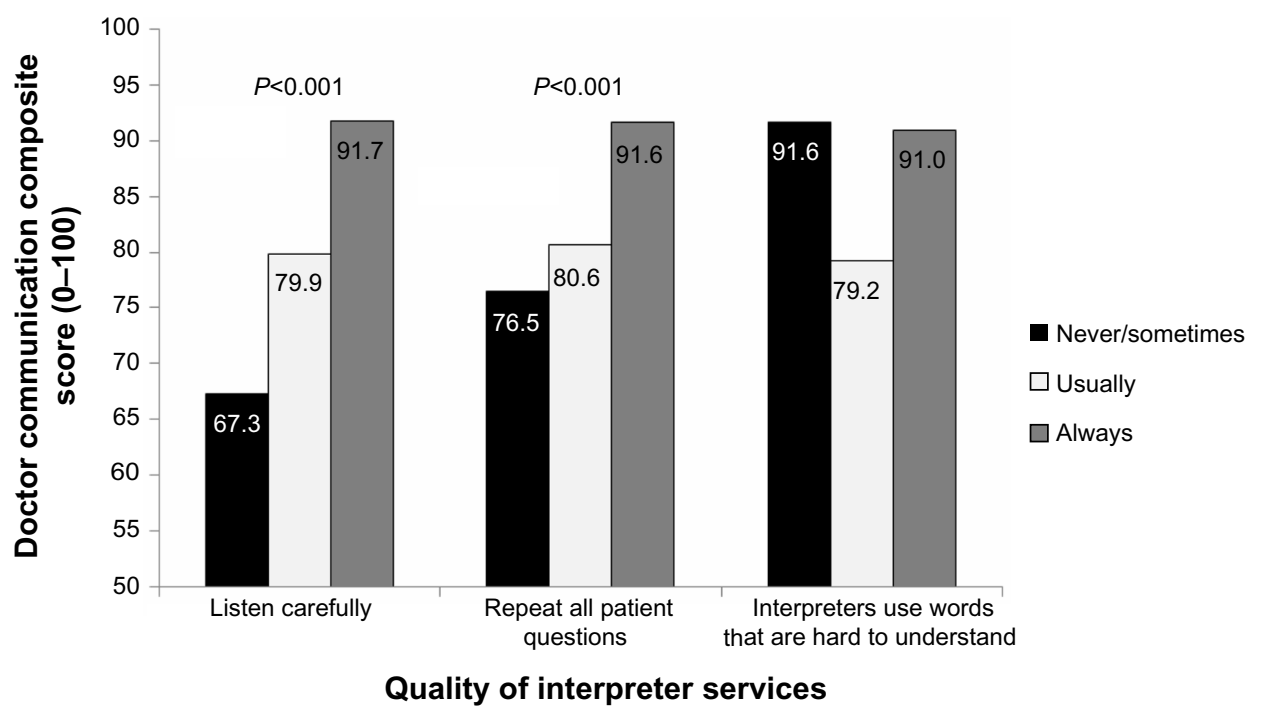

Figure I Doctor communication composite score and quality of interpreter services adjusted for patient characteristics.

Notes: Higher scores (range 0-100) indicate greater patient satisfaction with doctor communication; and the magnitude and significance of the results did not vary after adjusting for age, sex, education, marital status, income, insurance coverage, health status, survey wave, and site of care. 
the " interpreters use of words that are hard to understand" did not correlate with the doctor-patient communication and satisfaction with care scores. This question was negatively worded and it may have been difficult to understand. Alternatively, the use of medical words during the clinical encounter is hard for patients to understand regardless of who says them (eg, doctor or interpreter). Although this study focused on Latinos, more studies are needed to understand the views of patients towards interpreters from other backgrounds such as Chinese, Vietnamese, and Koreans. Prior studies have shown that interpreter use among Asian patients may help increase cancer prevention screening and is positively associated with perceived quality of care. ${ }^{21,22}$ The findings from this study are the first step in developing a set of survey items that measures patient experiences with the quality of interpretation provided by medical interpreters.

This study has several limitations. Our study sample is largely representative of low-income Latinos with a low level of education making the results nongeneralizable to other populations or to all Spanish-speaking Latinos. However, this group represents the growing Latino population in the US who will become insured under the Affordable Care Act. ${ }^{23}$ Participants were asked about encounters in a 6-month time frame and their responses to the survey questions are subject to recall bias, and socially desirable responses. Instrument bias cannot be excluded as a possible explanation for the results given that only two out of the three survey questions were associated with the outcome measures. Patient responses were also focused on interpretation experiences that generally occurred over several visits. Although the survey did not distinguish the type of interpreter used (eg, doctor, nurse, or other health professionals), these findings may be used to improve the patient-interpreter-provider experience. The survey questions were not designed or tested with patient input but were designed in an exploratory fashion by investigators with content expertise. ${ }^{13-15}$ Further research is needed to determine what aspects of interpretation are important for LEP patients and to examine patient experiences with the quality of interpretation and the relationship to clinical outcomes.

This study found that there is construct validity of a patient-reported measure of quality of interpretation with doctor communication and satisfaction with care when interpreters listen carefully and repeat all questions to doctor. Health systems across the country providing health services to an increasing Spanish-speaking LEP population may use these results to improve health care delivery and outcomes by incorporating research guided by patients.

\section{Acknowledgments}

Dr Talamantes was supported by the Veterans Affairs Office of Academic Affiliations through the Veterans Affairs/Robert Wood Johnson Clinical Scholars Program. Drs Moreno and Mangione received support from the University of California, Los Angeles (UCLA) and Resource Centers for Minority Aging Research Center for Health Improvement of Minority Elderly (RCMAR/CHIME) under National Institutes of Health/National Institute on Aging Grant P30-AG021684. Dr Moreno was supported by an National Institute on Aging K23-AG042961 Paul B Beeson award. Dr Mangione also received support from National Institutes of Health/National Center for Advancing Translational Sciences UCLA Clinical and Translational Science Institute Grant UL1TR000124. Dr Mangione holds the Barbara A Levey and Gerald S Levey Endowed Chair in Medicine, which partially supported her work. Dr Morales was supported by the National Center for Research Resources and the National Center for Advancing Translational Sciences, National Institutes of Health, through Grant 3UL1RR025014.

\section{Disclosure}

The authors report no conflicts of interest in this work.

\section{References}

1. Johnson TD, Rios M, Drewery PD, Ennis SR, Kim MO. People Who Spoke a Language Other Than English at Home by Hispanic Origin and Race: 2009. US Department of Commerce; 2010. Available from: http:// www.census.gov/prod/2010pubs/acsbr09-19.pdf. Accessed October 10, 2012.

2. Ryan C. Language Use in the United States: 2011. US Department of Commerce; 2013. Available from: http://www.census.gov/prod/2013pubs/ acs-22.pdf. Accessed November 6, 2012.

3. Guidance to Federal Financial Assistance Recipients Regarding Title VI Prohibition Against National Origin Discrimination Affecting Limited English Proficient Persons [webpage on the Internet]. Washington, DC: US Deparment of Homeland Security; 2002. Available from: http://www. dhs.gov/guidance-federal-financial-assistance-recipients-regarding-titlevi-prohibition-against-national. Accessed April 2, 2013.

4. Fernandez A, Schillinger D, Warton EM, et al. Language barriers, physician-patient language concordance, and glycemic control among insured Latinos with diabetes: the Diabetes Study of Northern California (DISTANCE). $J$ Gen Intern Med. 2011;26(2):170-176.

5. Traylor AH, Schmittdiel JA, Uratsu CS, Mangione CM, Subramanian U. Adherence to cardiovascular disease medications: does patient-provider race/ethnicity and language concordance matter? J Gen Intern Med. 2010;25(11):1172-1177.

6. Pippins JR, Alegria M, Haas JS. Association between language proficiency and the quality of primary care among a national sample of insured Latinos. Med Care. 2007;45(11):1020-1025.

7. Jacobs EA, Karavolos K, Rathouz PJ, Ferris TG, Powell LH. Limited English proficiency and breast and cervical cancer screening in a multiethnic population. Am J Public Health. 2005;95(8): $1410-1416$

8. Cheng EM, Chen A, Cunningham W. Primary language and receipt of recommended health care among Hispanics in the United States. J Gen Intern Med. 2007;22:283-288. 
9. National Standards on Culturally and Linguistically Appropriate Services (CLAS) in Health Care [webpage on the Internet]. US Department of Health and Human Services Office of Ministry Health; 2013. Available from: http://minorityhealth.hhs.gov/templates/browse. aspx?lvl=2\&lvlID=15. Accessed April 10, 2013.

10. Diamond LC, Wilson-Stronks A, Jacobs EA. Do Hospitals Measure up to the National Culturally and Linguistically Appropriate Services Standards? Med Care. 2010;48(12):1080-1087.

11. Jacobs EA, Shepard DS, Suaya JA, Stone EL. Overcoming language barriers in health care: costs and benefits of interpreter services. Am J Public Health. 2004;94(5):866-869.

12. Karliner LS, Jacobs EA, Chen AH, Mutha S. Do professional interpreters improve clinical care for patients with limited English proficiency? A systematic review of the literature. Health Serv Res. 2007;42(2): 727-754.

13. Moreno G, Morales LS. Hablamos Juntos (Together We Speak): Interpreters, Provider Communication, and Satisfaction with Care. J Gen Intern Med. 2010;25(12):1282-1288.

14. Moreno G, Tarn DM, Morales LS. Impact of Interpreters on the Receipt of New Prescription Medication Information Among Spanish-Speaking Latinos. Med Care. 2009;47(12):1201-1208.

15. Wu S, Ridgely MS, Escarce JJ, Morales LS. Language access services for Latinos with limited English proficiency: lessons learned from Hablamos Juntos. J Gen Intern Med. 2007;22 Suppl 2:350-355.

16. Gany F, Leng J, Shapiro E, et al. Patient satisfaction with different interpreting methods: A randomized controlled trial. J Gen Intern Med. $2007 ; 22: 312-318$
17. Mosen DM, Carlson MJ, Morales LS, Hanes PP. Satisfaction with provider communication among Spanish-speaking Medicaid enrollees. Ambul Pediatr. 2004;4(6):500-504.

18. Lee LJ, Batal HA, Maselli JH, Kutner JS. Effect of Spanish interpretation method on patient satisfaction in an urban walk-in clinic. J Gen Intern Med. 2002;17(8):640-645.

19. Kuo D, Fagan M. Satisfaction with methods of Spanish interpretation in an ambulatory care clinic. J Gen Intern Med. 1999;14(9):547-550.

20. Moreno MR, Otero-Sabogal R, Newman J. Assessing dual-role staffinterpreter linguistic competency in an integrated healthcare system. J Gen Intern Med. 2007;22 Suppl 2:331-335.

21. Dang J, Lee J, Tran JH, et al. The Role of Medical Interpretation on Breast and Cervical Cancer Screening Among Asian American and Pacific Islander Women. J Cancer Educ. 2010;25(2):253-262.

22. Green AR, Ngo-Metzger Q, Legedza AT, Massagli MP, Phillips RS, Iezzoni LI. Interpreter services, language concordance, and health care quality. Experiences of Asian Americans with limited English proficiency. J Gen Intern Med. 2005;20(11):1050-1056.

23. Gee ER. Eligible uninsured Latinos: 8 in 10 could receive health insurance, marketplace tax credits, Medicaid or CHIP. Washington, DC: Department of Health and Human Services, Office of the Assistant Secretary for Planning and Evaluation; 2014. Available from: http://aspe. hhs.gov/health/reports/2013/UninsuredLatinos/rb_uninsuredLatinos. pdf. Accessed August 13, 2014.
Patient Related Outcome Measures

\section{Publish your work in this journal}

Patient Related Outcome Measures is an international, peer-reviewed, open access journal focusing on treatment outcomes specifically relevant to patients. All aspects of patient care are addressed within the journal and practitioners from all disciplines are invited to submit their work as well as healthcare researchers and patient support groups.

\section{Dovepress}

The manuscript management system is completely online and includes a very quick and fair peer-review system. Visit http://www.dovepress. com/testimonials.php to read real quotes from published authors. 